\title{
Families created by in vitro fertilization (IVF) in Greece: Parenting stress and parental bonding at adolescence
}

ORIGINAL

\section{Abstract}

Background: As in vitro fertilization (IVF) had already been introduced since 1978, follow-up studies, are widely available. It has been speculated, that parents who have undergone fertility treatment, may be overprotective of their children due to the emotional, financial and physical barriers they had to surmount in order to conceive. In order to investigate if this speculation carries on to adolescence, we obtained information about experienced parenting stress and recalled parental bonding from (IVF) families and spontaneous conception (SC) families with adolescents.

Method: The sample of the study consisted of 50 dyads adolescents who were born after IVF and their parents, and 50 dyads adolescents born after spontaneous conception (SC). Participants completed questionnaires about parental bonding behavior and parental stress. Descriptive statistics, such as means, standard deviations, and frequencies, were used.

Results: Adolescents' age ranged from 14 to $18 \mathrm{yrs}$; mean age 15.94 (SD = 1.20) in IVF and 15.99 (SD = 1.21) in spontaneously conceived. The mean age of IVF and (SC) mothers was 48.38 (SD = 3.68) and 44.9 (SD $=3.59$ ) respectively. The mean age of IVF and (SC) fathers was 50.36 (SD = 5.85) and 48.32 (SD = 4.62) respectively. (SC) parents and especially SC fathers, showed statistically significant higher levels of parenting stress in comparison with their IVF counterparts. IVF mothers stated statistically significant higher levels of care and lower levels of overprotection to their offspring, in comparison to SC mothers. The same findings were applicable to IVF fathers as well.

Conclusion: In our study, lower levels of parental stress were found, among IVF parents. IVF families with adolescents seem to be well functioning in Greece, with respect to the economic and human crisis facing the country.
A.Sarantaki ${ }^{1}$,
D. Anagnostopoulos ${ }^{2}$,
D. Loutradis ${ }^{3}$,
G. Vaslamatzis ${ }^{2}$

1 Department of Midwifery, TEl of Athens, Greece.

2 Department of Psychiatry, Athens Medical School, University of Athens, Greece.

3 Department of Obstetrics \& Gynecology, Athens Medical School, University of Athens, Greece.

\section{Contact information:}

\section{Antigoni Sarantaki.}

Address: 8, Ikarias Str, Ano Ilisia, Athens, Greece.

Tel: 6977613848

ほ sarantaki.antigoni@gmail.com
Keywords
Parenting Stress; Parental Bonding; Care; Overprotection; IVF; Adolescence. 


\section{Introduction}

Parenthood is undeniably one of the most universally desired goals in adulthood. However, not all couples, who desire a pregnancy, will achieve one spontaneously. Global estimates suggest that nearly 72.4 million people, experience fertility problems and of these, 40.5 million are seeking infertility medical care. Infertility has been recognized as a public health issue worldwide by the World Health Organization (WHO) [1]. The decline in fertility since the 1970s, has been paralleled by the advances made in reproductive technology, since the birth of the first IVF baby, Louise Brown, in Britain, 37 years ago) [2] .

It may seem that the only difference between IVF and spontaneous conception is the conception itself. IVF involves the fertilization of an egg with sperm in the laboratory and the transfer of the resulting embryo, to the mother's womb. When the mother's egg and the father's sperm are used, both parents are genetically related to the child. However, there are a number of reasons, why having a child by IVF, may result in a rather different experience for parents. Couples undergo a lengthy and stressful procedure before their (much desired) child is born. There have been various assumptions, speculations and expectations from society and from the psychological and medical professions about the health, relationships and management of infertile couples. Therefore, parenthood, child interaction and child rearing, for couples being parents especially after IVF treatment, have been much focused. It has been suggested that the stress of infertility and its treatment may lead to parenting difficulties when a long - awaited baby is eventually born [3]. Burns [4] argued that parents who had difficulty in conceiving might become emotionally over-invested in their long awaited child.

Concerns have been raised about the potentially adverse consequences of assisted reproduction, for children's psychological development and parenting. It has been argued, for example, that dys- functional patterns of parenting may be a feature for these families, due to the difficulties experienced by the mothers and fathers in their quest for a child [5]. A number of researchers [6, 4, 7, 8, 9] also suggested that those who become parents after a period of infertility, may be overprotective of their children, or may have unrealistic expectations of them, or of themselves as parents, because of the difficulties they experienced in their attempt to conceive.

In short term studies on donor and IVF families, parenthood and child development have reported to be good $[10,11,12,13,9]$. Contrary to the concerns that have been raised regarding the potentially negative consequences of IVF for parenting, studies of these families, have generally found IVF parents to be well adjusted and to have good relationships with their children [14]. Van Balen and Trimbos - Kemper [15] suggest that the experience of infertility may be associated with improved motivation to have children and a greater awareness of the importance of parenthood. Most of these studies have approached the IVF families when the children were 2-8 years old, and compared them, with families who have adopted or donor conceived children, and with couples with spontaneously conceived children. Although multiple studies have shown that children born through artificial reproduction technologies (ARTs), function well in childhood $[16,17,18]$ little data have been gathered beyond it. Do these findings carry over into adolescence? Or fertility treatment rally lead to overprotective parents, who hinder the emotional development of their children at adolescence?

Adolescence is a critical time for identity formation and the development of autonomy from parents. Identity formation is a normal stage of development that concerns how an individual constructs meaning about their life [19]. It must be noted, that identity development occurs in a broader context and it is largely influenced by relationships within the family $[20,21]$. During adolescence these issues of identity 
become salient and parent - child conflict is most likely to occur [22]. Thus it is primarily at adolescence that difficulties for these children would be expected to arise [23]. Parents who have used ARTs, may be overprotective of their children, due to the emotional, financial and psychical obstacles, they had to overcome in order to conceive $[24,9]$. In earlier publications, it was suggested that parenting, in the case of IVF, becomes more difficult, when children grow older and - as a consequence- more autonomous and independent. Theoretical, clinical and empirical evidence, have suggested that issues of separation, autonomy and independence might be particularly at risk in families with history of infertility and IVF $[25,26,27]$.

As there is noticeably, still lack of knowledge, in the field of IVF parents and their adolescent offspring, the aim of the present study was to examine the difference between the parenthood experience of primiparous singleton IVF couples and the experience of couples who had become spontaneously pregnant with their first child, regarding maternal and paternal bonding, with respect to experienced parenting stress. All the IVF children were conceived using the mother's egg and the father's sperm and were thus, genetically related to both their parents.

\section{Methods}

\section{Sample and data Collection}

The data of this cross-sectional study were collected through a battery of questionnaires, between April 2012 and April 2014 from one of the largest public fertility units in Athens, Greece. Initially medical records of families with a singleton child, born from IVF conception between 1996 and 2000 were retrieved. Subsequently parents were invited by mail or telephone to participate in the study. Sixty five families with a singleton child, born from IVF conception were initially traced from the records of the fertility unit. Thirteen families were not reachable (e.g. they had either moved or they did not respond) and two parents of two families refused to participate. Non participation was mainly due to time constraints. Hence, 50 IVF adolescents and their parents agreed to take part in the overall study (response rate $77 \%$ ).

A control group was sampled of families with adolescents who were conceived spontaneously (SC) and were matched one to one, for sex and age ( \pm 1-4 months), with the study group of IVF adolescents. Seventy six adolescents and their parents, out of 112 families who initially were invited to take part, agreed to participate in the study (response rate $68 \%$ ). Twenty six families were excluded from the study since no matched IVF adolescent could be found. Therefore, the final control group consisted of 50 families with their adolescents, who were born spontaneously. Participants, who agreed to participate, received the questionnaire package. The questionnaires were completed at home by the participants themselves, without consulting their partners/parents and returned by pre-paid envelope to the fertility unit of the hospital.

\section{Measures}

Parental Bonding Instrument (PBI) [28] is an instrument measuring fundamental parental styles as perceived by the adolescent and includes two subscales termed 'care' and 'overprotection' or 'control'. The instrument includes 25 item questions, including 12 'care' items and 13 'overprotection' items. The measure is completed, by adolescents, for both mothers and fathers separately. Thus, each adolescent is asked to complete two copies of the PBI, one for his/her mother and one for his/her mother. Items are rated on a 4-point scale, ranging from " $0=$ very unlike" to " $4=$ very like". The overall "care" score range from 0 to 36 , the overall "overprotection score range from 0 to 39 and the higher the score the higher the parental bonding. A cut-off "care" score of 27 and 24 has been established for mothers and fathers respec- 
tively. In addition a cut-off "protection" score of 13.5 and 12.5 has been established for mothers and fathers respectively.

The Parental Stress Scale (PSS) [29] is a self-report questionnaire that consists of 18 items. It provides a measure that considers positive aspects of parenting as well as the negative, 'stressful' aspects traditionally focused on. It also attempts to measure the levels of stress experienced by parents and takes into account positive and negative aspects of parenting. Items represent positive (e.g. emotional benefits, personal development) and negative (demands on resources, restrictions) themes of parenthood. Respondents agree or disagree in terms of their typical relationship with their child or children. Items are rated on a 5- point scale, ranging from strongly disagree (1), to strongly agree (5). The overall score range from 18 to 90 and the higher the score the higher the parental stress.

Basic demographic information includes age, educational level, economic level and employment status. The educational level is categorized as low (up through elementary school), medium (high school certificate) and high (university degree). The annual income level is categorized as low (9.600-17.999€), medium (18.000-35.999€) or high (>35.000€). The employment status is categorized as employee in the private sector, employee in the public sector, free lancer, pensioner, manual worker or unemployed.

\section{Data analyses}

Statistical analysis was performed using SPSS version 21.0 (SPSS Inc., Chicago, IL). Univariate frequency distributions, means and standard deviations were calculated for the variables (demographic characteristics of the participants). Distribution analysis was performed using SPSS Explore procedure for evaluation of assumption of normality and the data found to be normally distributed. Therefore, parametric statistical tests were performed. Bivariate analyses were conducted, comparing IVF participants to SC participants. Differences between IVF families nad SC families were examined by using independent samples t-test and ANOVA for continuous variables and by using chi-square tests for categorical variables. Pearson's correlation was used to measure the associations between continuous variables.

\section{Ethics}

The Research and Ethics Committee of the General Hospital "Alexandra" as well as the scientific Committee of Aigineteio hospital, approved the study protocol. All parents and children were informed about the purpose of the study and that the collected data would be strictly confidential and used only for the purpose of the study. Eligible parents and their children were also assured that they could withdraw from the study at any time. All study participants signed an informed consent form.

\section{Results}

\section{Characteristics of the participants}

Adolescents' age ranged from 14 to $18 \mathrm{yrs}$. The mean age for the IVF group was $15.94(S D=1.20)$ and 15.99 (SD = 1.21) for the spontaneously conceived adolescents. The mean age of IVF mothers was 48.38 (SD = 3.68; range: 41-56yrs) and 50.36 (SD = 5.85; range: 38-65yrs) of IVF fathers respectively. For the control group of spontaneously conceived parents, the mean age of (SC) mothers was 44.9 ( $S D=3.59$; range: 38-53yrs) and 48.32 (SD = 4.62; range: $40-58 \mathrm{yrs}$ ) of (SC) fathers. Forty percent of IVF mothers had higher education (university degree), when most of SC mothers (52\%) had finished high school. More than half of women in both groups participated in the work force $(64 \%$ and $68 \%$ of IVF and SC mothers respectively) and had medium annual family income. Eighteen percent of the IVF participants and $30 \%$ of the SC, were pensioners. Forty two percent of IVF fathers had higher education (university degree), when more than 
half of SC fathers (52\%) had finished high school. The vast majority of fathers in both groups were employees (88\% IVF fathers and $84 \%$ SC fathers respectively). Forty two percent of IVF fathers were working in the private sector, while $6 \%$ of them were pensioners. The percentages for the SC group were $44 \%$ and $14 \%$ respectively.

The mean score of parenting stress for IVF mothers was 39.25 (8.27) and for SC mothers was 46.04 (7.38) while for IVF fathers was 43.48 (8.52) and for SC fathers was 48.84 (10.3). Independent ttest analyses revealed that spontaneous conception (SC) parents, showed statistically significant higher levels of parenting stress [ $p=0.000, p=0.006$ ] in comparison with their IVF counterparts (Table 1).

The mean score of care for IVF parents was 29.23 (5.13) and SC parents was 28.71 (6.15) while the overprotection score for IVF parents was 12.45(6.42) and for SC parents was 13.27 (6.64) (Table 2). As far as the scores for parental bonding subscales, care and overprotection, are concerned there were no statistically significant differences between groups (Table 2). In general, mothers (from both groups) stated significant higher levels of care and overprotection to their offspring ( $p=0.000$ and $p=0.025$, respectively), in comparison to fathers (from both groups).

\section{Correlations between demographic variables, bonding and parenting stress}

There was no significant relationship between age, educational level, income level, bonding and parenting stress. However, ANOVA revealed that pensioner SC mothers expressed statistically significant higher levels of parenting stress [Mean $=49.4$ (SD = 8.53)] than SC mothers who were employees [Mean $=44.9(S D=6.20)](p=0.027)$. All pensioner IVF fathers expressed statistically significant higher levels of parenting stress [Mean $=56.6(S D=6.04)$ ] than IVF fathers who were employees [Mean $=42.7$ $(S D=8.20)]$ ( $p=0.016)$. In addition, IVF fathers who were employees in the private sector [Mean =
Table 1. Means, standard deviations and p-values for parenting stress by family type.

\begin{tabular}{|l|l|l|l|l|l|}
\hline & IVF & SD & $\begin{array}{c}\text { Spontaneously } \\
\text { Conceived }\end{array}$ & \multicolumn{1}{|c|}{$\begin{array}{c}\text { S- } \\
\text { Value }\end{array}$} \\
\cline { 2 - 5 } & Mean & & Mean & & Value \\
\hline Mothers & 39.24 & 8.27 & 46.04 & 7.38 & .000 \\
\hline Fathers & 43.48 & 8.52 & 48.84 & 10.3 & .006 \\
\hline Both Parents & 41.36 & 8.62 & 47.44 & 9.02 & .000 \\
\hline
\end{tabular}

Table 2. Means, standard deviations and sig. (2-tailed) for parental bonding (care - overprotection).

\begin{tabular}{|c|c|c|c|c|}
\hline & \multicolumn{4}{|c|}{ Bonding } \\
\hline & \multicolumn{2}{|c|}{ Care } & \multicolumn{2}{|c|}{ Overprotection } \\
\hline & $\begin{array}{l}\text { Mean } \\
(S D)\end{array}$ & $\begin{array}{c}\text { Sig. } \\
\text { (2-tailed) }\end{array}$ & $\begin{array}{l}\text { Mean } \\
\text { (SD) }\end{array}$ & $\begin{array}{c}\text { Sig. } \\
\text { (2-tailed) }\end{array}$ \\
\hline All Mothers & $30.51(4.00)$ & .000 & 13.89 (5.99) & .025 \\
\hline All Fathers & $27.43(6.59)$ & & $11.83(6.89)$ & \\
\hline IVF Parents & $29.23(5.13)$ & .517 & $12.45(6.42)$ & .376 \\
\hline $\begin{array}{l}\text { Spontaneous } \\
\text { Conception } \\
\text { Parents }\end{array}$ & $28.71(6.15)$ & & $13.27(6.64)$ & \\
\hline IVF Mothers & 30.84 (3.99) & .413 & $13.7(5.80)$ & .753 \\
\hline $\begin{array}{l}\text { Spontaneous } \\
\text { Conception } \\
\text { Mothers }\end{array}$ & $30.18(4.02)$ & & $14.08(6.23)$ & \\
\hline IVF Fathers & $27.62(5.66)$ & .775 & $11.20(6.81)$ & .364 \\
\hline $\begin{array}{l}\text { Spontaneous } \\
\text { Conception } \\
\text { Fathers }\end{array}$ & $27.24(7.46)$ & & $12.46(6.99)$ & \\
\hline
\end{tabular}

Source: Research data

46.4 (SD = 9.01)] expressed statistically significant higher levels of parenting stress [Mean $=56.6$ (SD = 6.04)] than IVF fathers who were employees in the public sector [Mean = 36.6 (SD = 3.09)] or workers $(p=0.011)$.

\section{Correlations between parenting stress and bonding}

Mothers and fathers in both groups had statistically significant negative correlation between overprotection - bonding and care - bonding $(r=-0.535$, 
Table 3. Correlations between Bonding (care - overprotection) and parenting stress.

\begin{tabular}{|c|c|c|c|c|c|c|c|}
\hline & \multicolumn{7}{|c|}{ Bonding-care } \\
\hline & All Mothers & All Fathers & Both Parents & IVF Mothers & IVF Fathers & SC Mothers & SC Fathers \\
\hline \multicolumn{8}{|c|}{ Bonding-overprotection } \\
\hline $\begin{array}{l}\text { Pearson } \\
\text { Correlation }\end{array}$ & $-.535^{\star \star}$ & $-.678^{* *}$ & $-.545^{\star \star}$ & $-.377^{* *}$ & $-.594^{\star *}$ & $-.681 * *$ & $-.750 * *$ \\
\hline $\begin{array}{l}\text { Correlation } \\
\text { Coefficient }\end{array}$ & $-.562^{\star *}$ & $-.664^{\star *}$ & & & & & \\
\hline Sig. (2-tailed) & .000 & .000 & & .000 & .007 & .000 & .000 \\
\hline \multicolumn{8}{|c|}{ Parenting stress } \\
\hline $\begin{array}{l}\text { Pearson } \\
\text { correlation }\end{array}$ & & & $-.168^{*}$ & & & & \\
\hline Sig. (2-tailed) & & & .017 & & & & \\
\hline
\end{tabular}

$\mathrm{p}<0.001, \mathrm{r}=-0.678, \mathrm{p}<0.001)$. Parenting stress and parental bonding (care) were statistically significant and negatively correlated $(r=-0.168, p=0.017)$ (Table 3)

\section{Discussion}

As IVF had already been introduced since 1978, follow-up studies, are widely available, finding that psychosocial development of the child, psychological adjustment of the parents and parent-child interaction are comparable after IVF and spontaneous conception (SC) $[30,31,5,32,8,13,33,16,34$, 14], or even superior after IVF [30, 31, 5, 8, 35]. However, very little data have been gathered beyond childhood, especially in adolescence. In order to investigate if this speculation carries on to adolescence, we obtained information about experienced parenting stress and recalled parental bonding from IVF families and SC families with adolescents.

In our study, positive parent-child interactions and lower levels of parental stress were found, among IVF parents. It is possible that after a period of infertility, parents might appreciate the value of their child and parent more consciously. In addition, couples who use artificial reproduction technologies (ARTs), are on average older, than couples who conceive naturally, like in our study. This fact, allows them time to fulfill personal ambitions and develop more of a foundation for their relationships, something that may overshadow the stress of infertility [36]. Study findings confirm a body of research regarding high emotional involvement with their child, great parental competence and overall positive adjustment in IVF parents [37, 31, 11, 38]. It can be assumed that IVF couples are more oriented towards formation of a family. Couples, who have managed to maintain a functioning relationship despite infertility, might be more prepared for the difficult task of raising a child. The representation of optimal parental bonding types regarding maternal and paternal bonding, featured by a high level of care and low level of overprotection/control, among the IVF parents, was associated with lower level of parenting stress. One possible explanation of this association may be the theory of attachment [39]. The quality of a child's attachment is based on the quality of care the child receives. Perceptions of sensitive care will lead to the confidence that the caregiver will be responsive. This confidence of the caregiver's availability is described by Erikson [40] as trust and by Bowlby as secure attachment. Our findings are in line with Golombok [31], who have also found lower stress rates in mothers of single- 
tons born after artificial reproduction, as compared to SC mothers.

Adolescent-parent attachment has profound effects on cognitive, social and emotional functioning [41]. There is evidence that parents do make a difference, and that this difference operates through the nature of their attachment bond with their child $[42,43]$. Secure attachment is associated with less engagement in high risk behaviors, fewer mental health problems, and enhanced social skills and coping strategies.

The better parenting practices in older mother families have been attributed to the so-called maternal maturity hypothesis [44], that is, to the fact that older mothers have accrued life experiences, wisdom, financial and social resources, and a more varied coping repertoire that promotes a more responsive family environment [45].

Follow-up studies with children conceived with fertility treatment show that previously infertile mothers as compared to their never infertile counterparts show less parenting stress [46] and tend to be warmer and more emotionally involved with their children [31].

Older mothers have also been found to share more parenting tasks and rely significantly more on their partner during early infancy than do younger (on-time) mothers [46]. These results suggest that some benefits found in older mother families could be attributed to their partner and to relational characteristics rather than to benefits arising from older age. Results in fertile and infertile populations make clear that maternal age effects need to be considered in light of partner and relationship variables. However, it should be noted that these effects may vary between populations.

Older mothers may experience reproductive difficulties but they are also more likely to have completed a university education, to have a high employment status $[47,48]$, be satisfied with their work and perceive it to be important [48], and in terms of personality, to be more resilient, hardy [50, 49], autonomous, and less dependent on others [49]. In contrast, younger mothers tend to have more traditional attitudes toward the role of women in society, identify more with motherhood $[50,49]$ and be less rejecting of the negative aspects of care-giving than older mothers [50]. These person factors could lead younger and older mothers to provide different kinds of environments for their children (e.g., warmth, hostility) and/or to differences in maternal wellbeing (e.g., anxiety, depression). Child outcomes therefore need to be examined in relation to a wider context that includes family environment and parent wellbeing.

Pensioner IVF fathers and private sector employees, as well as SC pensioner mothers in the present study expressed statistically significant elevated levels of parenting stress. Greece has entered a long period of economic crisis with adverse effects on various aspects of daily life. The impact of the economic crisis on the mental health of the Greek population is pervasive [50]. It is acknowledged that macrosocial changes affect increasingly smaller social units and ultimately those microsocial phenomena directly influence parents and children in their families [51]. Economic hardship is known to be associated with a variety of physical and psychological problems in children, adolescents and adults [52]. McBride [53] concluded that the only consistent demographic variables related to fathers' experience of stress in the parent role was family income. Parents with lower economic status reported significantly higher levels of parenting stress. Various researchers note that economic status affects both husbands' and wives' parenting stress as well as their psychological well-being. Others, have noted that economic factors were strong predictors of personal and parenting difficulties [54, 55]

Financial crisis and worsened socio-economic conditions can be associated with greater parenting stress among pensioners who see their pensions decreasing more and more, every day, or employees in the private sector who face the threat of unem- 
ployment due to the fact that many companies cut down their staff. Given that the economic recession in Greece deepens, such a result was not surprising.

It is important to note, that all IVF adolescents in our study were genetically related to both their parents, so it is uncertain, whether these findings can be generalized to children, born through reproductive donation. The absence of genetic relatedness between one parent and the child, may have differential effects on psychological adjustment of adolescents and parent adolescent relationships. It would be beneficial, to gather more data from adolescents conceived through ARTs, in different family types. A limitation of the present study is that it focused on singleton children, to avoid the confounding effects of multiple births. As the current rate for multiple births following the use of ARTs, is $\sim 24 \%$ [56], the follow up of such families through adolescence, would further elucidate family functioning, following fertility treatment, due to the fact that parents of IVF twins or triplets, have been found to experience higher levels of parenting stress and difficulties in parenting than parents of IVF singletons [57].

In vitro fertilization was a groundbreaking technique that raised not only ethical concerns, but also psychological regarding the potentially negative impact on families created by this procedure. Although, creating families by means of assisted reproduction, has raised a number of concerns about potentially adverse consequences for parenting, the findings of the present study of IVF adolescents, add to the body of research on IVF children at a younger age, in showing that IVF couples are highly motivated and competent parents.

Our findings indicate that the stress or stigma of infertility do not negatively impact family functioning in IVF families with an adolescent child. It has been suggested that the incising use of IVF, likely removes the early stigma associated with the procedure and normalizes it [36]. IVF families with adolescent children seem to be functioning well in
Greece, with respect to the economic and human crisis facing the country.

\section{Conclusion}

Since in vitro fertilization (IVF) became available, around 5 million children have been born worldwide, through assisted reproductive technologies (ARTs) [58]. A number of concerns has been expressed for families formed through the new reproductive technologies (NRTs) and especially IVF. It has been proposed, that the experience of infertility and assisted reproduction has negative effects on child rearing and that idealization of parenthood make some couples unable to cope with the unpleasant aspects of parenting [59].

Contrary to the concerns that have been raised regarding the potentially negative consequences of IVF for parenting, the present study of IVF and SC families, have generally found IVF parents to be well adjusted and to have good relationships with their adolescent children. The IVF couples and their offspring were not deviant to normality with regards to parenthood. In fact the IVF families seem stable and harmonious. IVF parents stated less parenting stress compared to SC parents.

In conclusion the findings of the present study, underline the previously expressed conclusions that adolescents born through IVF have positive relationships with their parents and IVF assisted families in Greece, seem to be functioning well through adolescence.

\section{References}

1. Boivin J, Bunting L, Collins JA, Nygren KG. International estimates of infertility prevalence and treatment seeking: potential need and demand for infertility medical care. Human Reproduction. 2007; 22: 1506-12

2. Cox SJ, Glazebrook C, Sheard C, Ndukwe G and Oates M. Maternal self esteem after successful treatment of infertility. Fertility and Sterility. 2006; 85(1): 84-89

3. Owen L, Golombok S. Families created by assisted reproduction: Parent - child relationships in late adolescence. Journal of Adolescence. 2009; 32: 835-48 
4. Burns LH. An exploratory study of perceptions of parenting after infertility. Fam. Systems Med. 1990; 8: 177-89

5. Golombok S, Brewaeys A, Giavazzi MT, Guerra D, Mc Callum $\mathrm{F}$ and Rust J. The European Study of assisted reproduction families: the transition to adolescence. Human Reproduction. 2002; 17(3): 830-40

6. Mushin D, Spensley J and Barreda - Hanson M. Children of IVF. Clin. Obstetr. Gynecol. 1985; 12: 865-75

7. McMahon C, Ungerer J, Beaurepaire J, Tennant $C$ and Saunders D. Psychological outcomes for parents and children after in vitro fertilization: a review. J. Reprod. Infant Psychol. 1995; 13: 1-16

8. Van Balen F. Development of IVF children. Dev. Rev. 1998;18: 30-46.

9. Hahn CS and Di Pietro JA. In vitro fertilization and the family: Quality of parenting, family functioning and child psychosocial adjustment. Dev. Psychol. 2001; 37: 37-48

10. Golombok S, Cook R, Bish A and Murray C. Quality of parenting in families created by the new reproductive technologies: a brief report of preliminary findings. J. Psychosom. Obstetr. Gynaecol 1993.; 14: 17-22

11. Van Balen F. Child rearing following in vitro fertilization. J. Child Psychol. Psychiat. 1996;37(6): 687-93

12. Cook R. , Vatev I. , Michova Z. and Golombok S. The European study of assisted reproduction families: a comparison of family functioning and child development between Eastern and Western Europe J. Psychosom. Obstetr. Gynaecol. 1997;18: 203-12.

13. Gibson FL. , Ungerer JA. , McMahon C, Leslie GI and Saunders DM. The mother-child relationship following in vitro fertilization (IVF): infant attachment, responsivity and maternal sensitivity. J. Child Psychol. Psychiatr. 2002a;41: 1015-23

14. Golombok S and MacCallum F. Practitioner Review: Outcomes for parents and children following non-traditional conception: what do clinicians need to know? J. Child Psychol. And Psychiat. 2003; 44(3): 303-15

15. Van Balen F and Trimbos - Kemper TCM. Involuntary childless couples: Their desire to have children and their motives. J. Psychos. Obstetr. Gynecol. 1995.; 16: 137-144

16. Hahn CS. Psychosocial well being of parents and their children born after assisted reproduction. J. Pediatr. Psychol. 2001;26: 525-38

17. Bassatemur E, Sutcliffe A. Follow up of children born after ART. Placenta 2008; 29: 135-40

18. Wagenaar K, Huisman J, Cohen-Kettenis PT, Delemarre van de Waal HA. An overview of studies on early development, cognition and psychosocial well being in children born after in vitro fertilization. J. Dev. Behav. Pediatr. 2008.;29: 219-30

19. Erikson EH. Identity, Youth and Crisis System. Res. 1968;14: 154-59

20. Phinney J, Goossens L. Identity development in context. J. Adolesc. 1996; 19: 401-3

21. Grotevant HD, Von Korff L. Adoptive identity. In: Schwartz S, Luyckx K, Vignoles VL (eds). Handbook of Identity Theory and Research. New York: Springer. 2001

22. Coleman JC and Hendry L. The nature of adolescence. ( $2^{\text {nd }}$ ed. ). London: Routledge. 1990
23. Golombok S, MacCallum F and Goodman E. The "Test-Tube" Generation: Parent - Child Relationships and the Psychological Well - Being of In Vitro Fertilization Children at Adolescence. Child Develop. 2001; 72(2): 599-608.

24. Weaver SM, Clifford E, Gordon AG, Hay DM, Robinson J. A follow up study of successful IVF/GIFT couples: social-emotional well being and adjustment to parenthood. J. Psychos. Obstetr. Gynecol. 1993; 14: 5-16

25. Colpin H, Demyttenaere K and Vandemeulebroecke L. New reproductive technology and the family. The parent-child relationship following in vitro fertilization. J. Child Psychol. Psychiat. 1995;36: 1429-41

26. Colpin H. Parenting following medically assisted reproduction. University Press, Leuven. 1996

27. Hammer-Burns L. Parenting after infertility. In : Hammer-Burns $L$. and Covington SN (eds) Infertility counseling. A comprehensive handbook for clinicians. Parthenon Publishing, New York, London. 1999

28. Parker G, Tupling, $H$, and Brown, LB. A Parental Bonding Instrument. British Journal of Medical Psychology 1979; 52: 1-10.

29. Berry JO and Jones WH. The Parental Stress Scale: Initial psychometric evidence. Journal of Social and Personal Relationships 1995; 12(3): 463-72

30. Cederblad M, Friberg B, Ploman F. Intelligence and behaviour in children born after in vitro fertilization treatment. Human Reproduction 1996; 11: 2052-57

31. Golombok S, Brewaeys A, Cook R, Giavazzi MT, Guerra D, Mantovani A, van Hall E, Crosignani PG, Dexeus S. The European study of assisted reproduction families: family functioning and Child Development. Human Reproduction 1996;11: 2324-31

32. McMahon CA, Ungerer JA, Tennant $C$ and Saunders D. Psychosocial adjustment and the quality of the mother-child relationship at four months postpartum after conception by in vitro fertilization. Fertility and Sterility 1997; 68: 492-500

33. Gibson FL, Ungerer JA, Tennant CC and Saunders DM. Parental adjustment and attitudes to parenting after in vitro fertilization (IVF). Fertility and Sterility 2000b; 73: 565-74

34. Colpin $\mathrm{H}$ and Soenen S. Parenting and psychological development of IVF children: a follow up study. Human Reproduction 2002; 17(4): 1116-23

35. Montgomery TR, Aiello F, Adelman RD, Wasylyshyn N, Andrews MC, Brazelton TB, Jones GS, Jones HW Jr. The psychological status at school age of children conceived by in-vitro fertilization. Human Reproduction 1999; 14(8): 2162-65.

36. Colpin H, Bossaert G. Adolescents conceived by IVF: parenting and psychosocial adjustment. Human Reproduction 2008; 22: 2724-30

37. Golombok S, Cook R, Bish A, Murray C. Families created by the new reproductive technologies: quality of parenting and social and emotional development of the children. Child Dev. Apr. 1995; 66(2): 285-98 
38. McMahon CA, Gibson F, Leslie G, Cohen J, Tennant C. Parents of 5-year-old in vitro fertilization children: psychological adjustment, parenting stress, and the influence of subsequent in vitro fertilization treatment. J. Fam. Psychol. Sept. 2003; 17(3): 361-9

39. Bowlby J. Attachment and Loss. Attachment. Vol. 1. Harmondsworth, England: Penguin. 1971

40. Erikson EH. Childhood and Society. $2^{\text {nd }}$ edition. New York: Basic Books. 1963

41. Moretti MM. , Peled M. Adolescent - parent attachment: Bonds that support healthy development. Pediatr. Child Health 2004; 9(8): 551-55

42. Doyle AB, Moretti MM, Brendgen M, Bukowski W. Parent child relationships and adjustment in adolescence. Findings from HSBC and NLSCY Cycle 2 Studies. CAT number 032ss. H521900CYHS. 2002. Ottawa: Health Canada, Child and Family Division.

43. Moretti MM, Holland R. Navigating the journey of adolescence: Parental attachment and the self from a systematic perspective. In: Johnson S. , Whiffen V. (eds) Clinical Applications of Attachment Theory. New York: Guildford. 2003

44. Hofferth SL. The children of teen child bearers. In: S. L. Hofferth, C. D. Hayes (Eds. ), Risking the future: Adolescent sexuality, pregnancy and childbearing, National Academy Press, Washington DC. 1987: 174-206

45. Bornstein MH, Putnick DL, Suwalsky JTD, Gini M. Maternal chronological age, prenatal and perinatal history, social support, and parenting of infants; Child Development 2006; 77: 875892

46. Abbey A, Andrews FM, Halman LJ. Infertility and parenthood: does becoming parent increase well-being? Journal of Consulting and Clinical Psycholology 1994; 62: 398-403

47. Berryman JC, Windridge C. Maternal age and employment in pregnancy and after childbirth. Journal of Reproductive and Infant Psychology 1997; 15: 287-302

48. Robinson GE, Garner DM, Gare DJ, Crawford B. Psychological adaptation to pregnancy in childless women more than 35 years of age. American Journal of Obstetrics and Gynecology 1987; 156: 328-333

49. McMahon C, Gibson FL, Allen JL, Saunders D. Psychosocial adjustment during pregnancy for older couples conceiving through assisted reproductive technology. Human Reproduction 2007: 22: 1168-1174

50. Zavras D, Tsiantou V, Pavi E, Mylona K, Kyriopoulos J. Impact of economic crisis and other demographic and socio-economic factors on self - rated health in Greece. The European Journal of Public Health; October. 2012: 1-5

51. Elder GH Jr and Casp A. Economic Stress in Lives: Developmental Perspectives. Journal of Social Issues 1988; 44(4): 25-45

52. Lempers JD, Clark-Lempers D and Simons RL. Economic Hardship, Parenting, and Distress in Adolescence. Child Development; Feb. 1989; 60(1): 25-39

53. McBride BA. Parental support programs and paternal stress: An exploratory study. Early Childhood Research Quarterly 1991; 6: 137-149.
54. Conger RD, Elder GH, Lorenz FO, Conger KJ, Simons RL, Whitbeck LB, Huck S, \& Melby JN. Linking economic hardship to marital quality and instability. Journal of Marriage and the Family 1990; 52: 643-656.

55. Pittman, J. F. , Wright, C. A. , \& Lloyd, S. A. Predicting parenting difficulty. Journal of Family Issues 1989; 10: 267-286.

56. Murray SR, Norman JE. Multiple pregnancies following assisted reproduction technologies - A happy consequence or double trouble? Semin. Fetal Neonatal Med. 2014; 19: 222-27

57. Golombok S, Olivennes F, Ramogida C, Freeman T \& Rust J. Parenting and the psychological development of a representative sample of triplets conceived by assisted reproduction. Human Reproduction 2007; 22(11): 2896-2902

58. Eshre: Eshre Art fact sheet. In Embryology ESoHRa, editor 2011. http://www.eshre.eu/ESHRE/English/Guidelines-Legal/ART-factsheet/page.aspx/1061. Accessed 1/8/2012

59. Sydjö G, Wadsby M, Kjellberg S and Sydjö A. Relationships and parenthood in couples after assisted reproduction and in spontaneous primiparous couples: a prospective long term follow up study. Human Reproduction 2002; 17 (12): 3242-50

\section{Comment on this article:}

\section{f $\mathbb{B}$ in $8+\mathbf{S} P$}

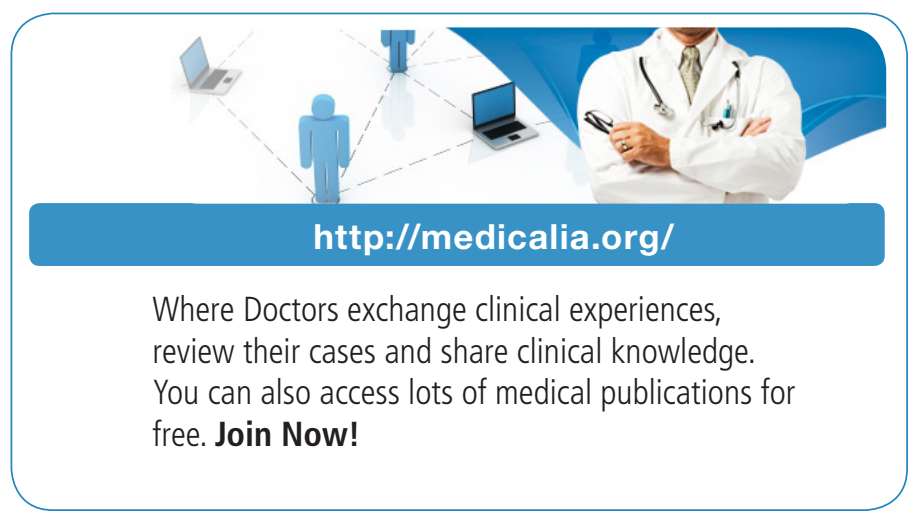

\section{Publish with iMedPub}

\section{http://www.imed.pub}

International Archives of Medicine is an open access journal publishing articles encompassing all aspects of medical science and clinical practice. IAM is considered a megajournal with independent sections on all areas of medicine. IAM is a really international journal with authors and board members from all around the world. The journal is widely indexed and classified Q1 in category Medicine. 